This item was submitted to Loughborough's Research Repository by the author.

Items in Figshare are protected by copyright, with all rights reserved, unless otherwise indicated.

\title{
How are UK academics engaging the public with their research? A cross- disciplinary perspective
}

\section{PLEASE CITE THE PUBLISHED VERSION}

http://dx.doi.org/10.1111/hequ.12088

\section{PUBLISHER}

(C) John Wiley and Sons

\section{VERSION}

AM (Accepted Manuscript)

\section{PUBLISHER STATEMENT}

This work is made available according to the conditions of the Creative Commons Attribution-NonCommercialNoDerivatives 4.0 International (CC BY-NC-ND 4.0) licence. Full details of this licence are available at: https://creativecommons.org/licenses/by-nc-nd/4.0/

\section{LICENCE}

CC BY-NC-ND 4.0

\section{REPOSITORY RECORD}

Chikoore, Lesley, Steve Probets, Jenny Fry, and Claire Creaser. 2019. "How Are UK Academics Engaging the Public with Their Research? A Cross-disciplinary Perspective”. figshare. https://hdl.handle.net/2134/20705. 


\title{
How are UK academics engaging the public with their research? A cross- disciplinary perspective
}

\begin{abstract}
This paper takes a cross-disciplinary perspective in examining the views and practices of public engagement with research by UK academics. Using a mixed method approach consisting of a survey questionnaire and interviews, the paper identifies the range of audience groups that can potentially be engaged with by academics, and shows that some audiences are more relevant to particular disciplinary groups than others. The paper also identifies the various public engagement activities undertaken by academics and finds that some academics are using creative ways of engaging the public, such as using the services of public relations firms to help in disseminating their research in traditional media outlets, and also by using social media. Essentially, the study reveals that some academics feel the pressure of engaging particular audiences at the expense of those that are relevant to them and that, academics in the main, are opposed to the notion of mandating public engagement as part of appraisal systems.
\end{abstract}

Keywords: Public engagement $\cdot$ Disciplinary typologies $\cdot$ Social media $•$ Academic autonomy

\section{Introduction}

This paper takes a cross-disciplinary perspective in examining the views and practices of public engagement with research by UK academics. It is based on a wider study of how 'research impact' is perceived by academics in different disciplinary contexts and the efforts they are making in planning and maximising the impact of their research. Public engagement in UK academia is an important aspect of research impact, particularly the "broader impact agenda” (Watermeyer, 2011, p.394). The paper explores patterns of public engagement across disciplines, with a particular focus on the types of audience. The paper also highlights the various activities undertaken by academics to engage the public and the opportunities and challenges they face in taking part in public engagement. 


\section{Background - Public engagement in UK academia: a brief history}

Public engagement covers diverse academic activities ranging from 'inreach’ (Featherstone, Wilkinson \& Bultitude, 2009, p.13) such as open days, and outreach such as exhibitions and public lectures, and has become increasingly prominent in academia over the past three decades. The phrase 'public engagement', as noted by the Centre for Higher Education Studies (2009, p.2), evolved from the term 'public understanding of science' which came into prominence in the UK in the 1980s; the idea being that if the public were to be more supportive of science, they had to understand better the issues behind it - one of the drivers of this was The Bodmer Report (Royal Society, 1985). In the late 1990s there was increased recognition of the need for a two-way communication (as opposed to the one-way communication characterising public understanding of science) between the scientific community and the public. The intention being that this would allow the public a "sense of ownership of science” by engaging with issues raised within the scientific community - this became known as 'public engagement' (Centre for Higher Education Studies, 2009, p.2).

\section{Moving towards a 'culture of change'}

Following on from the UK House of Lords Science and Technology Committee Report (2000), various initiatives began to emerge, most notably the National Co-ordinating Centre for Public Engagement (NCCPE), established in 2008 as part of the Research Councils, HE Funding Councils and Wellcome Trust-funded Beacons of Public Engagement initiative. The NCCPE was established to promote and inspire a 'culture of change' in how universities engage with the public, with six 'beacons' (or university-based collaborative centres) established to facilitate this (NCCPE, 2008). In recent years these funding bodies have sought to promote embedding the vision of a 'culture of change' into research organisations' mission statements. An example is the Concordat for Engaging the Public with Research (RCUK, 
2010), which spells out the Research Councils commitment to encouraging and supporting researchers to take part in public engagement.

\section{Public engagement and research 'impact'}

The increasing focus on public engagement has also been emphasised in research evaluation mechanisms such as the UK Research Excellence Framework (REF) 2014 which evaluated research activity against three criteria; environment, outputs, and broader impact. The 'broader impact' was a new criterion and sought to measure the impact of research beyond the academic community i.e. on the economy, policy or society. Inclusion of this broader impact criterion in the REF was inspired by Australia’s Research Quality Framework (which was never actually implemented following a change in government in 2008) (Kalucy et al. 2009). Research evaluation mechanisms in other countries, including New Zealand's Performance-Based Research Fund and the Netherlands’ Standard Evaluation Protocol (SEP) have incorporated broader impact in their assessment systems albeit with varying emphasis in the weighting criteria and different terminology; for example, one of SEP's evaluation criteria adopted the term 'societal relevance' to refer to 'the social, economic and cultural relevance of research” (VSNU, KNAW \& NOW, 2009, p.10).

The emergence of this broader impact criterion in research evaluation has meant that in addition to teaching and research, universities are increasingly expected to have a "third mission” (de Jong et al., 2014, p.89), that of prioritising the exploitation of knowledge beyond the academic community and into society as a whole. Public engagement becomes relevant within this context of the 'third mission' as a mechanism for disseminating research that also allows participation of non-academic audiences, some of whom may potentially go on to 'use' the research, and create impact. 


\section{Audiences for public engagement}

So who then are meant by the 'public' in the phrase 'public engagement'? Does this relate specifically to the general public, or does it include a mix of other non-academic groups such as charities, local government, industry and schools? The NCCPE (2014a, n.p.), a leading advocate for public engagement, accepts that the word 'public' "creates as many problems as it solves”. Consequently, for some academics, interpretations of what constitutes the 'public' are ambiguous, and some are uncertain as to what an academic-public interface might look like (Watermeyer, 2011, p.396). The NCCPE (2014b) suggests schools, colleges and further education, families and children, local communities, industry, and policy makers as examples of audience groups who can be referred to as the 'public'. Indeed the literature considers the 'public' as diverse audience groups that can be engaged with; for example Davies (2013, p.730) noted a wide range of activities such as 'knowledge transfer activities/working with industry', 'giving a public talk' and presenting at a museum/science centre. Moreover, the Royal Society (2006) Science Communication report showed that many disparate audiences (non-governmental organisations, journalists and schools) were ranked highly by the broad range of academics included in the study. Other studies have gone on to categorise audiences into broad groups such as business, public, and third sector (Abreu, et al., 2009). This study therefore considers the 'public' as all non-academic audiences (including the general public) that can potentially be engaged with by academics.

\section{Disciplinary differences in public engagement}

As there is a wide range of audiences that can potentially be engaged by academics, it is likely that some audiences are more relevant or important in some disciplines than in others. D’Este \& Perkmann's (2011) study on engagement with industry, surveyed academics in ten disciplines from the engineering and physical sciences, but did not explore whether any differences existed between the disciplines, hence they did not consider whether academics in 
mathematics exhibit the same attitudes towards public engagement as those in electrical and electronic engineering, for example. Another study by the Royal Society (2006) considered factors affecting public engagement by academics in the sciences and engineering disciplines; but as with the D’Este \& Perkmann (2011) study, it did not take into account differences within the broad disciplinary groups considered.

Whilst D’Este \& Perkmann (2011) and Royal Society (2006), which focused on academics in science and engineering disciplines, a number of studies have sought to gain the perspective of the social sciences, arts and humanities. Davies' (2013) study of public engagement activity of contract research staff included staff $(n=273)$ from a wide range of broad disciplinary groups: biological and biomedical sciences, physical sciences and engineering, social sciences, arts and humanities disciplines. Davies (2013, p.731), however, stated that there was "little opportunity" for proceeding to make disciplinary comparisons in her data as she found little variation in public engagement activity between the broad disciplinary groups. Davies (2013, p.731) nevertheless makes a recommendation for future studies to address public engagement activity in different disciplinary contexts and suggests a larger survey and in-depth interviews with academics as suitable data collection tools.

Abreu et al.'s (2009) large scale survey of academics $(n=22,170)$ in engineering and materials science, physics and mathematics, health sciences, social sciences, arts and humanities, and biology, chemistry and veterinary science, found there to be broad disciplinary differences with regards to academic interactions with three sectors: public, voluntary and private. Academics in the health sciences had the highest academic interactions with both the public and voluntary sector; whereas for the private sector, academics from engineering and material science disciplines reported the highest interactions. The survey offers the benefit of generalisation as it was based on a large sample (18\% of the UK 
academic population); however, it does not offer insight as to why individual academics in specific broad disciplinary groups engage with particular audiences.

The studies above highlight two key aspects - firstly, some studies (Royal Society, 2006; D’Este \& Perkmann, 2011) have tended to treat academics in different disciplines as a single homogeneous group with regards to public engagement activity. Secondly, the studies that have considered disciplinary differences in practices or attitudes towards public engagement, have categorised broad disciplinary groups in different ways (Abreu et al., 2009; Watermeyer, 2011, Davies, 2013). What is lacking from the current literature therefore, is a framework by which to make systematic comparisons across disciplines.

\section{Discipline taxonomies}

Discipline taxonomies can be used to categorise disciplines, according to sociological and epistemological factors, in other words, the culture of a discipline. Kuhn (1962, p.12) asserted the existence of a 'paradigm' - 'a cluster of beliefs' that serves to provide a consistent account of most of the phenomena of interest in the discipline and dictates how research should be interpreted in that discipline. Kuhn's (1962) work resulted in various studies, the most notable being by Biglan (1973a, pp.201-202) who adopted the label 'hard' to distinguish those disciplines (for example, chemistry) that subscribe to a single body of theory (the paradigm), from 'soft' disciplines in which content and method tends to be rather idiosyncratic, such as history. Biglan (1973a, p.202) used the labels 'pure' and 'applied' to identify the way scholars view academic disciplines in relation to application to practical problems. He distinguished applied disciplines such as education, engineering, and agricultural sciences from pure disciplines in the physical sciences, social sciences and humanities. 


\section{Becher's (1987) typology}

Becher (1987) extended Biglan’s (1973a) taxonomy by giving more detailed consideration to the nature of knowledge and cultural aspects of disciplines. Becher (1987) argued that this would help overcome the clustering of disciplines into broad administrative groups that were treated as homogenous groups for policy purposes. Becher's (1987) framework classifies disciplines into four groups - hard/pure, soft/pure, hard/applied and soft/applied - based on epistemological and sociological factors.

Table 1: Becher’s (1987) typology of knowledge and cultural structures in disciplines

Becher, and Trowler (2001, p.65), however acknowledge a limitation with all discipline classification systems by noting that there is no "standard verification procedure or set of concepts” that uniquely characterise each particular discipline.

Discipline taxonomies have been applied in a number of studies in higher education, for example; how academic training influences academics' behaviour (Del Favero, 2005), academics attitudes towards internationalisation (Agnew, 2013), and paradigmatic approaches of academics’ working on multidisciplinary projects (Gardner, 2013). There seems to be no study however that has applied disciplinary taxonomies in the context of public engagement by academics. This exploratory study investigates this by use of Becher's (1987) typology and looks at whether there is an association between the disciplinary group to which an academic belongs and

i) whether they have undertaken public engagement.

ii) the type of audience that they view as relevant to their research. 
Moreover the paper discusses the types of public engagement activities academics have undertaken, and their experiences in taking part in those activities.

\section{Methodology}

The study upon which this paper used mixed methods, consisting of an online, selfadministered questionnaire survey and semi-structured interviews with UK academics. The analysis is based on statistical (Pearson Chi-square) calculations to test the association between disciplinary groups and various variables, whereas the interviews gave an opportunity to probe on questions relating to practices and attitudes towards public engagement.

\section{The survey questionnaire}

\section{Designing the survey}

Respondents were asked to select their main, and any additional research areas from a list of Units of Assessment (UoA) - thirty-six categories into which research activity could be submitted for the REF 2014 (HEFCE, 2010). To assign the 36 REF UoA to Becher's (1987) disciplinary groups, an integrated taxonomy by Del Favero (2005), consisting of 98 disciplines (as shown in Table 2 below) was used as a reference tool. Del Favero (2005) combined various studies based on Biglan's (1973a,b) seminal work on discipline classification to come up with an integrated list of disciplines classified into hard/pure, soft/pure, hard/applied, soft/applied groups;

Table 2: Del Favero's (2005) integrated list of 98 disciplines classified in four disciplinary groups

These 98 disciplines were then mapped onto the $36 \mathrm{UoA}$; as a result 31 out of 36 were successfully mapped (Table 3). For the remaining 5 (in italics), the researchers used prior knowledge from the literature on disciplinary classification by Biglan (1973), Becher (1987, 1989), Becher \& Trowler (2001) to assign the most suitable quadrant. For example, most 
engineering disciplines were allocated to the hard/applied group, as shown below, hence the ‘civil and construction engineering’ UoA being assigned to that quadrant.

Table 3: The 36 UoA categorised into the four disciplinary groups

Respondents were then classed into one of the four disciplinary groups; hard/pure, soft/pure, hard/applied and soft/applied shown above; plus an additional group - interdisciplinary, for those respondents who had selected one or more additional disciplines not in the same group as their main discipline. For example, if a respondent chose Sociology, then History, they would be categorised as Soft/Pure as both disciplines belong to that group. However, if they selected Sociology then Biological Sciences, they would be classed as interdisciplinary, as Biological Sciences belongs to the hard/pure group as opposed to Sociology’s soft/pure group. The frequencies in each disciplinary group are shown in Fig 1 below:

Figure 1: Numbers of respondents in each disciplinary group

The centre bubble represents those classified as interdisciplinary, that is, their research straddled more than one disciplinary group. Preliminary analyses using Chi-square tests based on the five disciplinary groups, however, found that due to the low response to the questionnaire from certain groups, for example the hard/pure disciplinary group, there were low expected counts (i.e. less than 5) in one or more cells in the majority of the tests, rendering them invalid. Therefore, to minimise this 'loss of statistical power' (Field, 2009, p.692), rather than assigning respondents' research areas into the five disciplinary groups, a method that allowed comparing soft with hard disciplines, then pure with applied disciplines was devised. This method still retained the integrity of basing comparisons on the degree that researchers in a discipline subscribe to a single body of theory i.e. paradigm (hard v soft) and 
the concern of their research in application to practical problems (pure v applied). Figure 2 shows the proportions of respondents in the disciplinary groups following these changes.

Figure 2: Proportion of respondents in the different disciplinary groups

Fig 2 illustrates the two comparisons plus a 'Both Dimensions' group which identifies those whose research either straddles between the hard and soft disciplinary groups or between the pure and applied disciplinary groups. Appendix A illustrates an SPSS software screenshot of how respondents were categorised.

\section{Administering the survey}

Survey respondents were drawn from fifteen English universities, all within one hundred miles from the researchers' institution. The survey was open over an eight week period between January and March 2014, and was sent online through heads of all departments/schools, requesting them to circulate to 'research-active' staff. Twenty-three per cent (111/493) of heads of schools/departments are known to have circulated the survey, leading to a total of 260 survey responses.

\section{The interviews}

Following the survey, twenty-four academics were interviewed; twenty were recruited through the survey whilst four were recruited through referrals from other academics. The majority (18) of the interviews were done face-to-face, in interviewees' offices, whilst five were done via Skype and one was done over the telephone. A purposive and convenience sampling strategy was used; purposive sampling in the sense that the aim was to ensure all disciplinary groups were represented, and convenience sampling for the reason that the 100 mile radius from the researchers' institution would be cost-effective and also allow the interviewer more flexibility in dealing with unforeseen circumstances such as cancelled or 
rescheduled appointments. Interview data were analysed with the aid of NViVo software, using a thematic analysis approach (Braun \& Clarke, 2006). Table 4 shows the profiles of the interviewees:

Table 4: Profiles of interviewees

Table 4 illustrates the diversity of the interviewees in relation to disciplines and years of research experience. Moreover, interviewees were drawn from a wide range of universities from 11 of the fifteen universities that took part in the survey. For purposes of confidentiality, participants were assured that neither their name nor the name of their institution would be published.

\section{Findings and Discussion}

Seventy-nine percent (205/260) of the questionnaire respondents indicated that they had undertaken some form of public engagement activity with their research over the past five years. This is broadly in line with other related studies which have also shown that the majority of researchers had taken part in some form of public engagement activity - 74\% (Royal Society, 2006) and 68\% (Davies, 2013).

\section{Distribution of respondents in the disciplinary groups}

The proportions of respondents who took part in public engagement were more or less equal; across all disciplinary groups (Fig 3, Fig 4)

Figure 3: Hard v Soft disciplinary group distribution of respondents who took part in public engagement

Figure 4: Pure v Applied disciplinary group distribution of respondents who took part in public engagement 
Chi-square tests did not identify any association between the Hard-Soft (Chi-square=0.06, $\mathrm{df}=2, \mathrm{p}>0.05$ ) and Pure-Applied (Chi-square $=0.5, \mathrm{df}=2, \mathrm{p}>0.05$ ) disciplinary groups and whether or not respondents had taken part in public engagement. In other words, neither the degree that academics in a discipline subscribe to a paradigm (Hard-Soft) nor the concern of their research in application to practical problems (Pure-Applied) has a bearing on whether or not a researcher takes part in public engagement.

\section{Public engagement and research experience}

The tests however showed that there was an association between academics' years of research activity and whether or not they had undertaken any public engagement activity (Chi-square=26.79, df=5, $\mathrm{p}<0.05$ ) (Fig. 5).

Figure 5: Research experience distribution of respondents who took part in public engagement

As researchers become more experienced, they are generally more likely to take part in public engagement activities; this was confirmed in the interviews by one of the researchers (SA3, business and management studies) who had less than 5 years research experience, who stated that it was only "senior people" that are invited to present at university-hosted lecture presentations to business practitioners. Another interviewee, SA4, in the same discipline as SA3 but with more research experience, explained that her 20 years of research experience had allowed her to establish extensive networks - both practitioners and policy-makers in her field of employment policy, some of whom had invited her to present her research at annual events.

\section{Types of public engagement activities}

Survey respondents were then asked to state the specific activities they had undertaken (Fig. $6)$.

Figure 6: Types of public engagement activities $(n=205)$ 
'Presented to a professional audience' was the most common public engagement activity, undertaken by almost three quarters (73\%) of respondents. Academics were also using traditional media such as radio and TV (32\%) and newspapers/magazines (41\%) to engage the public. There was evidence from the interviews that some academics - SP1 (politics and international studies) and SA3 (business and management studies) - use the services of public relations firms to help disseminate their research in traditional media outlets such as newspapers and magazines. SA3 for example, stated how this had helped in getting her research disseminated "to people who might actually want to use it".

\section{Public engagement and social media use}

In addition to traditional media, academics were making efforts in engaging the public through social media, by using social networking sites such as Facebook and Twitter (31\%), blogs (25\%) and podcasts (9\%) (Fig. 6). This can be contrasted with a related study which showed that only $10 \%$ of researchers were 'interacting online with the public' (Davies, 2013). Although there was no statistical difference with regards to the proportions of respondents using social media from both comparisons of disciplinary groups (hard v soft; pure v applied), the qualitative data did imply some disciplinary group differences and highlighted a number of issues in relation to using social media to engage the public.

Interview data showed that there was a relationship between use of social media in engaging other researchers within the academic community and in engaging non-academic audiences, with apparent differences between two disciplinary groups in particular - the hard/pure and the soft/applied. It seems those interviewees, particularly from the hard/pure disciplinary group, who saw social media as an 'unsuitable' channel for disseminating their research to the academic community, and in the main, did not use social media to engage with the public. For example, one interviewee described his research community as 'conservative' (HP5, chemistry), whilst another, stated that "we do not communicate our research like this" (HP3, 
computer science). This can be contrasted with some interviewees in the soft/applied discipline, for example SA6 who described colleagues in his research community - media and cultural studies - as "very digitally engaged" and SA4 (business and management studies) who described having a 'Twitter network' consisting of journalists, politicians and trade unionists.

Another reason for use/non-use of social media can be attributed to generational differences. Of the three types of social media shown in Fig 6, whilst statistical tests did not identify any association between academics' years of research experience and using blogs and podcasts to engage with the public, they showed that there was an association (Chi-square $=17.8, \mathrm{df}=5$, $\mathrm{p}<0.05)$ with social networking sites - the most commonly used type of social media by survey respondents. Fig 7 below shows that use of social networking sites was higher for less experienced (0-17 years) researchers.

Figure 7: Research experience and use of social networking sites

The interviews also identified generational differences and hesitancy to use technology as reasons for whether or not academics used social media to engage the public with their research. For example, HP1, a biological scientist referred to himself as a "technophobe” who does not use social media in either his personal or professional life, whilst INT3 (public health services \& sociology) stated that she did not feel "particularly IT literate or competent" - this seemed to be a recurring theme:

"I should be doing more with them! I struggle with that a little bit, and I think that's got more to do with my age than anything else, because all of this is sort of new to me, I know it’s been around for a quite a while". (SP5, English literature and history)

“I'm afraid, that's a generational thing, I'm afraid... Facebook and Twitter, I've not personally been involved with.” (HA4, public health services)

The underlying theme in the quotes above is a hesitancy to use technology as a result of generational differences. In summary, use/non-use of social media in engaging the public 
with research can be attributed to a mix of factors that range from disciplinary cultures and personal circumstances such as generational differences and hesitancy to use technology.

\section{Relevant audiences}

Questionnaire respondents were asked to state how important it was to engage with the following eleven audience groups; Policy Institutes, Political Parties, Charities, Local Government, Supranational Bodies, International Bodies, Schools, Industry, Government Departments, Professional Organisations, and the General Public. Statistical analyses showed no association with either the Hard v Soft or Pure v Applied disciplinary groups for the first six audience groups listed above. For the remaining five, Table 5 below illustrates the associations found. The emboldened text indicate the disciplinary group(s) in which a greater proportion of respondents viewed a particular audience as 'extremely/very important'.

Table 5: Chi-square test results of most relevant audiences to disciplinary groups

Looking at all the five audience groups in Table 5, only two groups - Schools and Industry showed an association with the Hard v Soft disciplinary groups. In both instances a greater proportion of respondents from the Hard and Both Dimensions discipline groups viewed Schools and Industry as relevant audiences than those in the Soft discipline group. With regard to the Pure $\mathrm{v}$ Applied comparison, whereas respondents in Applied and Both Dimensions discipline groups viewed Industry, Professional Organisations and Government Departments as relevant audiences, when it came to the General Public, it was respondents from Pure and Both Dimensions discipline groups who viewed them as more relevant. This suggests that, while academics from Pure disciplines are happy to engage with the General Public, for academics in Applied disciplines, because of the importance of external sources of influence on their research and a higher degree of concern for application to practical problems as characterised by Biglan (1973a,b), engaging with specific groups such as 
Industry and Professional Organisations is important to them. Such engagement allows academics to gain insights into their own research area (Abreu et al., 2009) and also gives an opportunity for access to funds and other resources in future (D’Este \& Perkmann, 2011).

The interviews shed light on some of the experiences faced by academics when trying to engage relevant audiences with their research:

\section{Institutional influence on public engagement}

There was evidence from the interviews that academics felt they were being actively encouraged by their institution to target one particular audience - schools. SP3 (history) for example, felt that her university encouraged engaging with schools, "probably to raise aspirations rather than us disseminating our research”. The same opinion was given by HP1 (biological sciences) who mentioned that he felt public engagement activities at his university were "to increase its profile and probably attracting more students in this competitive environment". This confirms findings by Watermeyer (2011, p.398) who noted how some academics saw their institutions viewing public engagement as a 'public relations campaign' rather than as an activity of learning and sharing knowledge with audience groups.

There was further evidence of some academics feeling pressured to target audience groups that were irrelevant to their research. For example, SA4 (business and management studies) stated that, because she belonged to a business school she was expected to target business or law firms:

"...vice chancellors tend to like it when their business schools or their schools of management are going off to talk to PWC or Accenture or some big law firm or whatever, and that's kind of not what I do - absolutely, emphatically not what I do... and they don't get, usually why you would be in a business school if you don't do that.” (SA4, business and management studies)

Other academics such as SA2 (education) preferred public engagement not only being actively encouraged by institutions but also being “formalised as part of an appraisal system”. This was an interesting opinion which the interviewer investigated further in subsequent 
interviews. Most interviewees, particularly from Pure (as opposed to Applied) disciplines did not seem to share SA2's view, as illustrated in the quotes below:

“...it would certainly disadvantage us, it would certainly put a label of 'uselessness' on people like me, which I'd strongly object to, I think we are pretty useful... I think we would be disadvantaged by this...” (HP3, computer science)

"If I was forced to do it, it wouldn’t be as pleasurable. Ok, we're at work perhaps work shouldn't be always as pleasurable, though I think people should be given the room to devise their own ways of accessing the public attention.” (SP5, English literature and history)

It seems the reason why HP3 did not view formalising public engagement favourably was his concern that his research as too complex to explain to lay audiences. SP5, on the other hand, although she had carried out engagement activities such as displays in the local library, was concerned that there was not much interest in her research area (Victorian and Gothic literature) as opposed to some of her colleagues, who specialised in football history which was more contemporary and more popular with the public. This corroborates findings by Levitt et al. (2010, p.22) who noted the role of fashions and trends in 'shaping' public interest in academic research, particularly that in the arts and humanities.

\section{Conclusions}

This paper has shown that Becher's (1987) typology can be operationalised in investigating researchers' practices and views towards public engagement. A key finding is that no association exists between the disciplinary group to which an academic belongs and whether or not they have taken part in public engagement. However, an association does exist between certain disciplinary groups and particular audiences, whereby some audiences are more relevant to some disciplinary groups than others; for example, the general public were found to be more relevant to academics in Pure disciplines as opposed to those in Applied disciplines.

The study also found that those academics with more research experience are more likely to take part in public engagement than those with less experience. Moreover, some academics 
are using creative ways of engaging the public with their research, with some using PR firms whilst others are using social media. Use/non-use of social media in engaging the public with research can be attributed to a mix of factors that range from disciplinary cultures to personal circumstances such as generational differences and hesitancy to use technology.

Finally, although the majority of academics viewed taking part in various forms of public engagement favourably, the study pointed to academics valuing autonomy in deciding which audiences to engage. In addition, mandating public engagement as part of an appraisal system was widely viewed unfavourably, particularly by researchers from Pure (as opposed to Applied) disciplines. This suggests that although public engagement should be encouraged by institutions, academics should still have the autonomy to decide who they wish to engage with and whether or not they wish to take part in public engagement in the first place.

Appendix A: SPSS excerpt of how respondents were allocated into disciplinary groups

\begin{tabular}{|c|c|c|c|c|c|c|c|}
\hline & Q1_JobTit & Q5_Discip & Q5aCat1 & Q5bCat2 & Q5cCat3 & HardVSoft & PureVAppli... \\
\hline 1 & Professor & Business and Ma... & Sociology & & & Soft & Both dime... \\
\hline 2 & Professor & Business and $\mathrm{Ma}$... & & & & Soft & Applied \\
\hline 3 & Professor & Business and $\mathrm{Ma}$... & & & & Soft & Applied \\
\hline 4 & Professor & Art and Design: .... & & & & Soft & Pure \\
\hline 5 & Senior Lecturer & Art and Design: ... & Philosophy & & & Soft & Pure \\
\hline 6 & Senior Lecturer & Business and $\mathrm{Ma}$... & & & & Soft & Applied \\
\hline 7 & Senior Lecturer & Theology and Rel... & & & & Sott & Pure \\
\hline 8 & Reader & Physics & & & & Hard & Pure \\
\hline 9 & Professor & General Engineer... & Aeronautical, Me... & Public Health, He... & Computer Scienc... & Hard & Applied \\
\hline 10 & Other & Sport and Exerci... & & & & Soft & Applied \\
\hline 11 & Senior Lecturer & Allied Health Prof.. & Psychology, Psy... & Biological Scienc... & & Both dimensions & Both dime... \\
\hline 12 & Research Associ... & Psychology, Psy... & Art and Design: .... & Aeronautical, Me... & & Both dimensions & Both dime... \\
\hline
\end{tabular}

For respondent 1 for example, who selected Business and Management Studies (a soft/applied discipline), and an additional selection of Sociology (a soft/pure discipline), when it came to allocating them in the Hard or Soft discipline group, the respondent fell under the Soft discipline group. When it came to allocating them into either the Pure or Applied discipline groups however, because respondent 1's research straddled both the pure and the applied dimensions, the phrase 'Both dimensions' was used to identify their research 
area. Furthermore, for respondent 7, who selected only Theology and Religious Studies; a soft/pure discipline, when it came to allocating them into either the Hard or Soft discipline group, the respondent fell under the Soft discipline group. Also, when it came to allocating them into either the Pure or Applied discipline group, they fell under the Pure discipline group. The same principles of allocation were used throughout.

\section{References}

Abreu, M., Grinevich, V., Hughes, A. \& Kitson, M. (2009).

http://www.jbs.cam.ac.uk/fileadmin/user_upload/centre-for-business-

research/downloads/special-reports/specialreport-knowledgeexchangeacademics.pdf., last accessed 21 February 2015.

Agnew, M. (2013). Strategic planning: an examination of the role of disciplines in sustaining internationalisation of the University. Journal of Studies in International Education, 17(2), pp.183-202.

Centre for Higher Education Policy Studies (2009). The challenges for 21st century science: a review of the evidence base surrounding the value of public engagement by scientists, http://webarchive.nationalarchives.gov.uk/20120708131021/http://interactive.bis.gov.uk/scie nceandsociety/site/all/files/2010/02/Benneworth-FINAL2.pdf., last accessed 26 November 2015.

Becher, T. (1987). The disciplinary shaping of the profession. In: Clark, B.R. (ed.). The Academic Profession. Berkeley: University of California Press, pp.271-303.

Becher, T. \& Trowler, P.R. (2001). Academic tribes and territories: intellectual enquiry and the culture of disciplines ( $2^{\text {nd }}$ ed.). Milton Keynes: The Society for Research into Higher Education \& Open University Press.

Biglan, A. (1973a). The characteristics of subject matter in different academic areas. Journal of Applied Psychology, 57(3), pp.195-203.

Biglan, A. (1973b). Relationships between subject matter characteristics and the structure and output of university departments. Journal of Applied Psychology, 57(3), pp.204-213. 
D’Este, P. \& Perkmann, M. (2011). Why do academics engage with industry? The entrepreneurial university and individual motivations. The Journal of Technology Transfer, 36(3), pp.316-339.

Davies, S.R. (2013). Research staff and public engagement: a UK study. Higher Education, 66(6), pp. 725-739.

de Jong, S., Barker, K., Cox, D., Sveinsdottir, T. \& Van den Besselaar, P. (2014).

Understanding societal impact through productive interactions: ICT research as a case. Research Evaluation, 23(2), pp.89-102.

Del Favero, M. (2005). The social dimension of academic discipline as a discriminator of academic deans' administrative behaviours. The Review of Higher Education, 29(1), pp.6996.

Featherstone, H., Wilkinson, C. \& Bultitude, K. (2009). Public engagement map: report to the Science for All Expert Group, http://eprints.uwe.ac.uk/11593/1/PE-MAP-FINAL.pdf., last accessed 18 April 2015.

Gardner, S.K. (2013). Paradigmatic differences, power, and status: a qualitative investigation of faculty in one interdisciplinary research collaboration on sustainability science.

Sustainability Science, 8(2), pp. 241-252.

HEFCE (2010). Units of assessment and recruitment of expert panels, http://www.ref.ac.uk/media/ref/content/pub/unitsofassessmentandrecruitmentofexpertpanels/ 01_10.pdf., last accessed 16 January 2015.

HEFCE (2011). Decisions on assessing research impact,<http://www.ref.ac.uk/media/ref/content/pub/decisionsonassessingresearchimpact/01_ 11.pdf., last accessed 16 January 2015.

House of Lords Science and Technology Committee, (2000), http://www.publications.parliament.uk/pa/ld199900/ldselect/ldsctech/38/3801.htm., last accessed 24 November 2014.

Kalucy, L., Jackson Bowers, E., McIntyre, E., Hordacre, A-L \& Reed, R. (2009). Exploring the impact of primary health care research. Final Report Stage 2 Primary Health Care Research Impact project, 
http://www.phcris.org.au/phplib/filedownload.php?file=/elib/lib/downloaded_files/publicatio ns/pdfs/phcris_pub_8108.pdf., last accessed 30 November 2014.

Kuhn, T.S. (1962). The structure of scientific revolutions. Chicago: University of Chicago Press.

Levitt, R., Celia, C., Diepeveen, S., Chonaill, S.N., Rabinovich, L. \& Tiessen, J. (2010). Assessing the impact of arts and humanities research at the University of Cambridge. Cambridge: RAND Europe, http://www.rand.org/content/dam/rand/pubs/technical_reports/2010/RAND_TR816.pdf., last accessed 3 October 2014.

NCCPE (2008). The Beacons of Public Engagement, http://www.publicengagement.ac.uk/sites/default/files/publication/nccpe_bridging_the_gap_b rochure_0_0.pdf., last accessed 23 January 2015.

NCCPE (2014a). Who are the public? <http://www.publicengagement.ac.uk/explore-it/whoare-public., last accessed 23 January 2015.

NCCPE (2014b). Who to engage with? http://www.publicengagement.ac.uk/plan-it/whoengage-with., last accessed 23 January 2015.

RCUK (2012). Concordat for Engaging the Public with Research, http://www.rcuk.ac.uk/RCUK-prod/assets/documents/scisoc/NCCPEIntrooverviewp8.pdf., last accessed 21 November 2014.

The Royal Society (1985). The Bodmer Report: The Public Understanding of Science. Royal Society: London, https://royalsociety.org/ /media/Royal_Society_Content/policy/publications/1985/10700.pdf., last accessed 22 November 2014.

The Royal Society (2006). Science Communication: survey of factors affecting science communication by scientists and engineers, https://royalsociety.org/ /media/Royal_Society_Content/policy/publications/2006/11111113 95.pdf., last accessed 2 December 2015.

VSNU, KNAW \& NOW (2009). Standard Evaluation Protocol 2009-2015: Protocol for research assessment in the Netherlands, http://www.knaw.nl/sep., last accessed 22 July 2015. 
Watermeyer, R. (2011). Challenges for university engagement in the UK: towards a public academe? Higher Education Quarterly, 65(4), pp.386-410. 


\section{Tables}

Table 1: Becher's (1987) typology of knowledge and cultural structures in disciplines

\begin{tabular}{|c|c|c|}
\hline & Hard & Soft \\
\hline Pure & $\begin{array}{l}\text { Pure sciences } \\
\text { Knowledge structure } \\
\text { Cumulative; atomistic (crystalline/tree- } \\
\text { like); concerned with universals, } \\
\text { quantities, simplification; resulting in } \\
\text { discovery/explanation. } \\
\text { Cultural structure } \\
\text { Competitive, gregarious; politically well } \\
\text { organised; relatively high publication } \\
\text { rate; task oriented. } \\
\text { Example discipline } \\
\text { Physics }\end{array}$ & $\begin{array}{l}\text { Humanities and pure social sciences } \\
\text { Knowledge structure } \\
\text { Reiterative; holistic (organic/river-like); } \\
\text { concerned with particulars, qualities, } \\
\text { complication; resulting in } \\
\text { understanding/interpretation. } \\
\text { Cultural structure } \\
\text { Individualistic, pluralistic; loosely } \\
\text { structured; relatively low publication rate; } \\
\text { person oriented. } \\
\text { Example disciplines } \\
\text { Humanities - History } \\
\text { Pure social science - Anthropology }\end{array}$ \\
\hline Applied & $\begin{array}{l}\text { Technologies } \\
\text { Knowledge structure } \\
\text { Purposive, pragmatic (know-how via } \\
\text { hard knowledge); concerned with mastery } \\
\text { of physical environment; resulting in } \\
\text { products and techniques. } \\
\text { Cultural structure } \\
\text { Entrepreneurial, cosmopolitan; } \\
\text { dominated by professional values; patents } \\
\text { can be substitutable for publications; role } \\
\text { oriented. } \\
\text { Example discipline } \\
\text { Mechanical Engineering }\end{array}$ & $\begin{array}{l}\text { Applied Social Sciences } \\
\text { Knowledge structure } \\
\text { Functional, utilitarian (know-how via soft } \\
\text { knowledge); concerned with enhancement } \\
\text { of [semi-] professional practice; resulting } \\
\text { in protocols and procedures. } \\
\text { Cultural structure } \\
\text { Outward looking; uncertain in status; } \\
\text { dominated by intellectual fashions; } \\
\text { publication rates reduced by } \\
\text { consultancies; power oriented. } \\
\text { Example discipline } \\
\text { Education }\end{array}$ \\
\hline
\end{tabular}

Source: Becher (1987, p.289) 
Table 2: Del Favero’s (2005) integrated list of 98 disciplines classified in four disciplinary groups

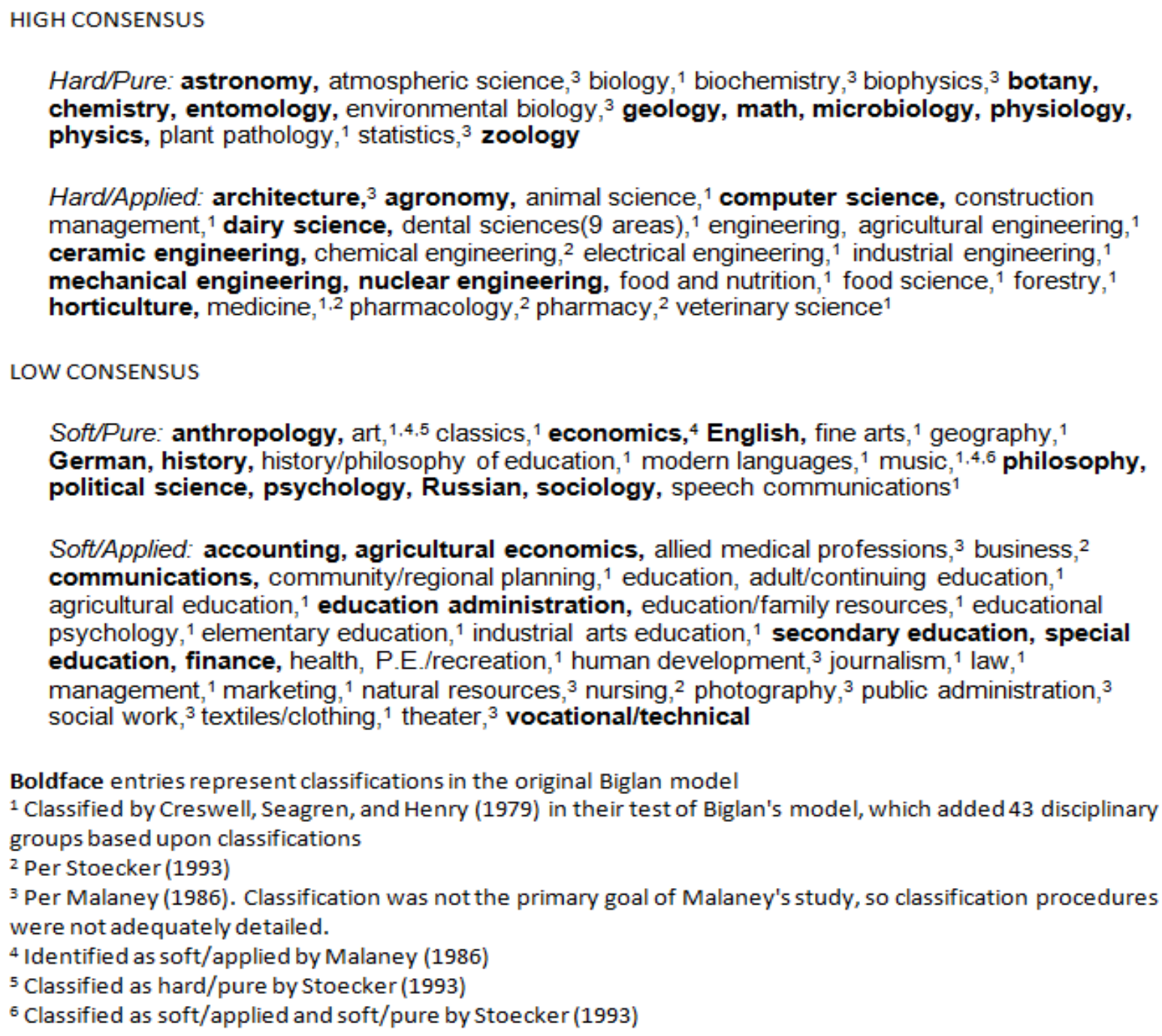

\section{LOW CONSENSUS}

Soft/Pure: anthropology, art, ${ }^{1,4,5}$ classics, ${ }^{1}$ economics, ${ }^{4}$ English, fine arts, ${ }^{1}$ geography ${ }^{1}$ German, history, history/philosophy of education, ${ }^{1}$ modern languages, ${ }^{1}$ music $, 1,4,6$ philosophy, political science, psychology, Russian, sociology, speech communications ${ }^{1}$

Soft/Applied: accounting, agricultural economics, allied medical professions, ${ }^{3}$ business, ${ }^{2}$ communications, community/regional planning, ${ }^{1}$ education, adult/continuing education, ${ }^{1}$ agricultural education, ${ }^{1}$ education administration, education/family resources ${ }^{1}$ educational psychology ${ }^{1}$ elementary education, ${ }^{1}$ industrial arts education, ${ }^{1}$ secondary education, special education, finance, health, P.E./recreation, ${ }^{1}$ human development, ${ }^{3}$ journalism, ${ }^{1}$ law ${ }^{1}$ management, ${ }^{1}$ marketing, ${ }^{1}$ natural resources, ${ }^{3}$ nursing ${ }_{,}^{2}$ photography ${ }_{,}^{3}$ public administration, ${ }^{3}$ social work ${ }_{,}^{3}$ textiles/clothing, ${ }^{1}$ theater, ${ }^{3}$ vocational/technical

Boldface entries represent classifications in the original Biglan model

${ }^{1}$ Classified by Creswell, Seagren, and Henry (1979) in their test of Biglan's model, which added 43 disciplinary groups based upon classifications

2 Per Stoecker (1993)

${ }^{3}$ Per Malaney (1986). Classification was not the primary goal of Malaney's study, so classification procedures were not adequately detailed.

${ }^{4}$ Identified as soft/applied by Malaney (1986)

${ }^{5}$ Classified as hard/pure by Stoecker (1993)

${ }^{6}$ Classified as soft/applied and soft/pure by Stoecker (1993)

Source: Del Favero (2005, p.92). NB: 'consensus' in this context refers to the degree to which academics subscribe to a single body of theory (or paradigm). 
Table 3: The 36 UoA grouped into the four disciplinary groups

\begin{tabular}{|c|c|c|}
\hline & Hard & Soft \\
\hline Pure & $\begin{array}{l}\text { - Biological Sciences } \\
\text { - Chemistry } \\
\text { - Earth Systems \& Environmental } \\
\text { Sciences } \\
\text { - Mathematical Sciences } \\
\text { - Physics }\end{array}$ & $\begin{array}{l}\text { - Anthropology \& Development } \\
\text { Studies } \\
\text { - Art \& Design: History, Practice \& } \\
\text { Theory } \\
\text { - Classics } \\
\text { - Economics \& Econometrics } \\
\text { - English Language \& Literature } \\
\text { - Geography, Environmental Studies } \\
\text { \& Archaeology } \\
\text { - History } \\
\text { - Modern Languages \& Linguistics } \\
\text { - Music, Drama, Dance \& Performing } \\
\text { Arts } \\
\text { - Philosophy } \\
\text { - Politics \& International Studies } \\
\text { - Psychology, Psychiatry \& } \\
\text { Neuroscience } \\
\text { - Sociology } \\
\text { - Theology \& Religious Studies }\end{array}$ \\
\hline Applied & $\begin{array}{l}\text { - Aeronautical, Mechanical, Chemical } \\
\text { and Manufacturing Engineering } \\
\text { - Agriculture, Veterinary \& Food } \\
\text { Science } \\
\text { - Allied Health Professions, Dentistry, } \\
\text { Nursing \& Pharmacy } \\
\text { - Architecture, Built Environment \& } \\
\text { Planning } \\
\text { - Clinical Medicine } \\
\text { - Civil \& Construction Engineering } \\
\text { - Computer Science \& Informatics } \\
\text { - Electrical \& Electronic Engineering, } \\
\text { Metallurgy \& Materials } \\
\text { - General Engineering } \\
\text { - Public Health, Health Services \& } \\
\text { Primary Care }\end{array}$ & $\begin{array}{l}\text { - Area Studies } \\
\text { - Business \& Management Studies } \\
\text { - Communication, Cultural \& Media } \\
\text { Studies, Library \& Information } \\
\text { Management } \\
\text { - Education } \\
\text { - Law } \\
\text { - Social Work \& Social Policy } \\
\text { - Sports \& Exercise Sciences, Leisure } \\
\text { \& Tourism }\end{array}$ \\
\hline
\end{tabular}


Table 4: Profiles of interviewees

\begin{tabular}{|c|c|c|}
\hline & Hard & Soft \\
\hline Pure & $\begin{array}{l}\text { - HP1: Reader, 24-29 years, Biological } \\
\text { Sciences } \\
\text { - HP2: Lecturer, 6-11 years, Physics } \\
\text { - HP3: Senior Lecturer, 12-17 years, } \\
\text { Computer Science \& Informatics } \\
\text { - HP4: Reader, 30+years, Computer } \\
\text { Science \& Informatics } \\
\text { - HP5: Professor, 30+ years, Chemistry }\end{array}$ & $\begin{array}{l}\text { - SP1: Lecturer, 1-5 years, Politics and } \\
\text { International Studies } \\
\text { - SP2: Senior Lecturer, 18-23 years, } \\
\text { Politics and International Studies } \\
\text { - SP3: Senior Lecturer, Lincoln, 6-11 } \\
\text { years, History } \\
\text { - SP4: Professor, 12-17 years, Politics and } \\
\text { International Studies \& Sociology } \\
\text { - SP5: Senior Lecturer, 12-17 years, } \\
\text { English Language and Literature \& } \\
\text { History }\end{array}$ \\
\hline Applied & $\begin{array}{l}\text { - HA1: Lecturer, 1-5 years, Architecture, } \\
\text { Built Environment \& Planning } \\
\text { - HA2: Senior Research Fellow, 12-17 } \\
\text { years, Allied Health Professions } \\
\text { - HA3: Research Associate, 6-11 years, } \\
\text { Electrical and Electronic Engineering } \\
\text { - HA4: Research Associate, 30+ years, } \\
\text { Public Health Services } \\
\text { - HA5: Professor, 12-17 years, } \\
\text { Architecture, Built Environment \& } \\
\text { Planning }\end{array}$ & $\begin{array}{l}\text { - SA1: Senior Research Fellow, 12-17 } \\
\text { years, Education } \\
\text { - SA2: Lecturer, 6-11 years, Education } \\
\text { - SA3: Lecturer, 1-5 years, Business and } \\
\text { Management Studies } \\
\text { - SA4: Professor, 18-23 years, Business } \\
\text { and Management Studies } \\
\text { - SA5: Research Fellow, 24-29 years, Art } \\
\text { \& Design: History, Practice \& Theory } \\
\text { - SA6: Professor, 12-17 years, } \\
\text { Communication, Cultural \& Media Studies } \\
\text { Library \& Information Management }\end{array}$ \\
\hline \multicolumn{3}{|c|}{$\begin{array}{l}\text { Interdisciplinary } \\
\text { - INT1: Senior Lecturer, 18-23 years, Clinical Medicine + Computer Science \& Informatics } \\
\text { - INT2: Lecturer, 6-11 years, General Engineering + Education } \\
\text { - INT3: Research Fellow, 1-5 years, Public Health Services + Sociology }\end{array}$} \\
\hline
\end{tabular}


Table 5: Chi-square test results of most relevant audiences to disciplinary groups

\begin{tabular}{|c|c|c|}
\hline Type of audience & Hard v Soft & Pure v Applied \\
\hline Schools & $\begin{array}{l}\text { Greater proportion of } \\
\text { respondents in Hard } \\
(47.3 \%) \text { than in both Soft } \\
(28.2 \%) \text { and Both } \\
\text { Dimensions (31.6\%) } \\
\text { disciplinary groups }\end{array}$ & No association. \\
\hline Industry & $\begin{array}{l}\text { Greater proportion of } \\
\text { respondents in Both } \\
\text { Dimensions ( } 73.7 \% \text { ) \& } \\
\text { Hard (65.9) disciplinary } \\
\text { groups than in the Soft } \\
\text { disciplinary group (43.5\%) }\end{array}$ & $\begin{array}{l}\text { Greater proportion of } \\
\text { respondents in Applied } \\
\text { (63.2\%) and Both } \\
\text { Dimensions (62.5\%) than in } \\
\text { the Pure disciplinary group } \\
(42.2 \%)\end{array}$ \\
\hline Professional Organisations & No association & $\begin{array}{l}\text { Greater proportion of } \\
\text { respondents in Both } \\
\text { Dimensions (78.6\%) and } \\
\text { Applied (73.7\%) } \\
\text { disciplinary groups than in } \\
\text { the Pure (53.3\%) } \\
\text { disciplinary group }\end{array}$ \\
\hline Government Departments & No association & $\begin{array}{l}\text { Greater proportion of } \\
\text { respondents in Both } \\
\text { Dimensions (60.7\%) and } \\
\text { Applied (50.0\%) } \\
\text { disciplinary groups than the } \\
\text { Pure }(36.7 \%) \text { disciplinary } \\
\text { group }\end{array}$ \\
\hline The General Public & No association & $\begin{array}{l}\text { Greater proportion of } \\
\text { respondents in the Pure } \\
(67.8 \%) \text { and Both } \\
\text { Dimensions (60.7\%) } \\
\text { disciplinary groups than in } \\
\text { the Applied (49.1\%) } \\
\text { disciplinary group }\end{array}$ \\
\hline
\end{tabular}




\section{Figures}

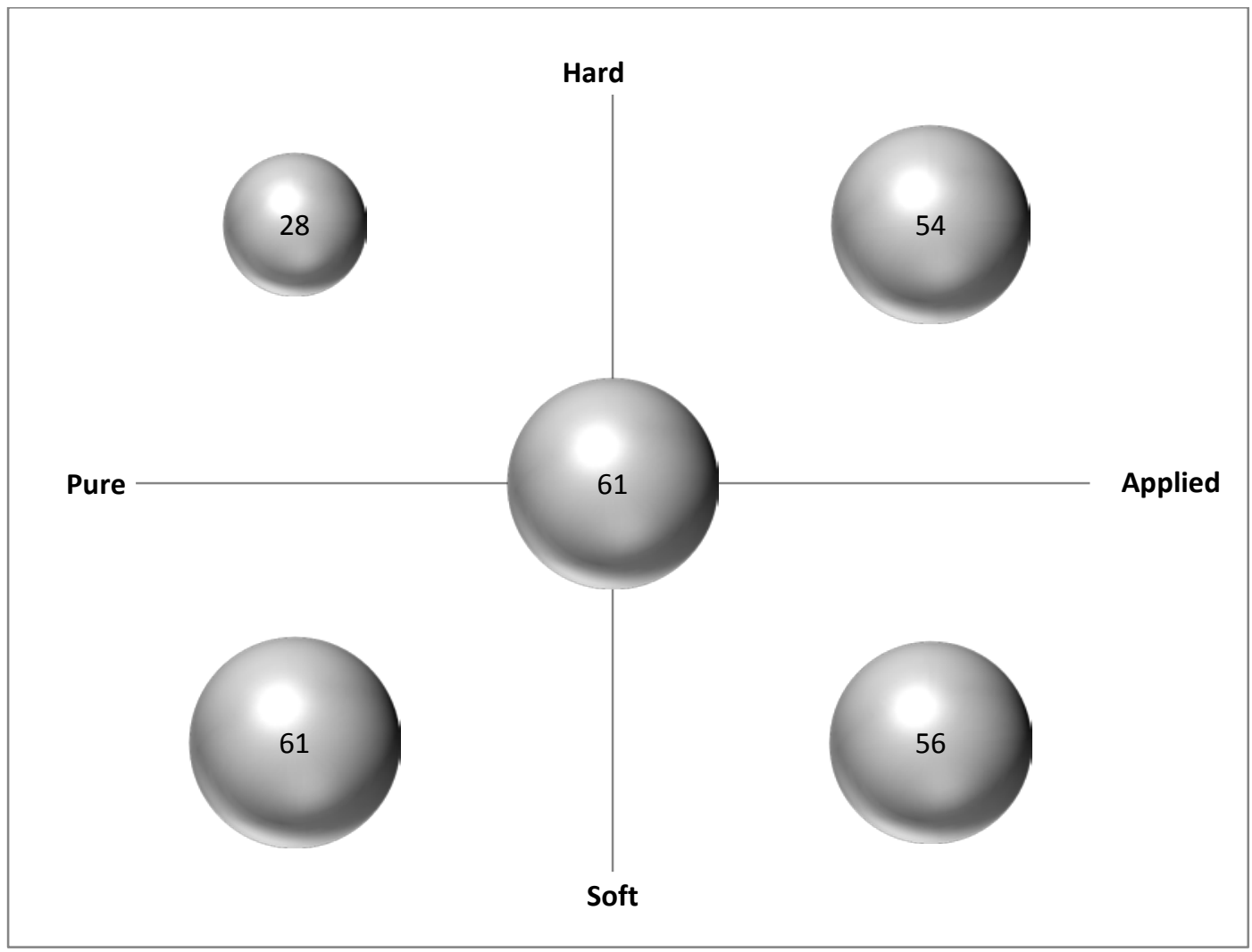

Figure 1: Numbers of respondents in each disciplinary group 


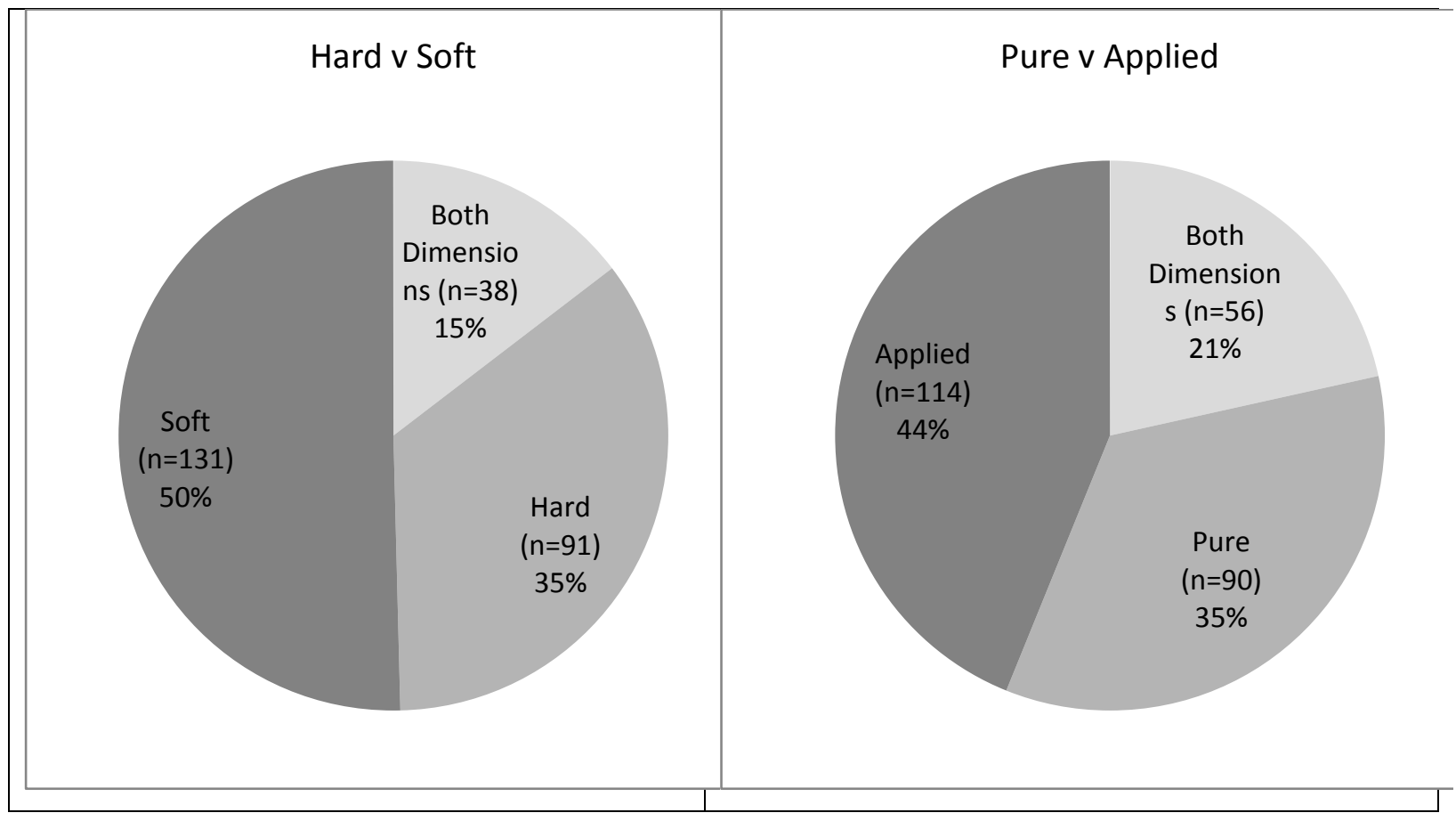

Figure 2: Proportion of respondents in the different disciplinary groups

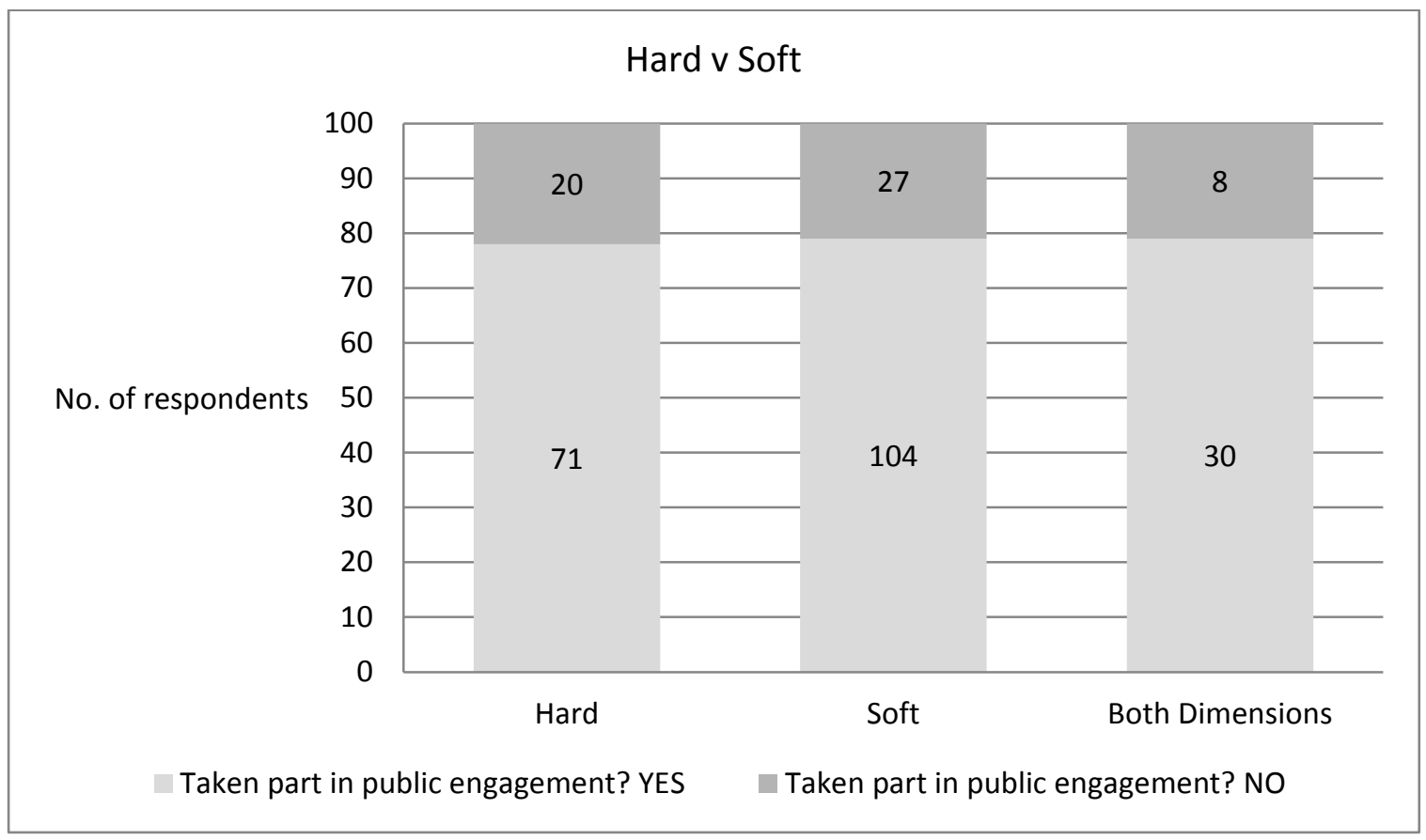

Figure 3: Hard v Soft disciplinary group distribution of respondents who took part in public engagement 


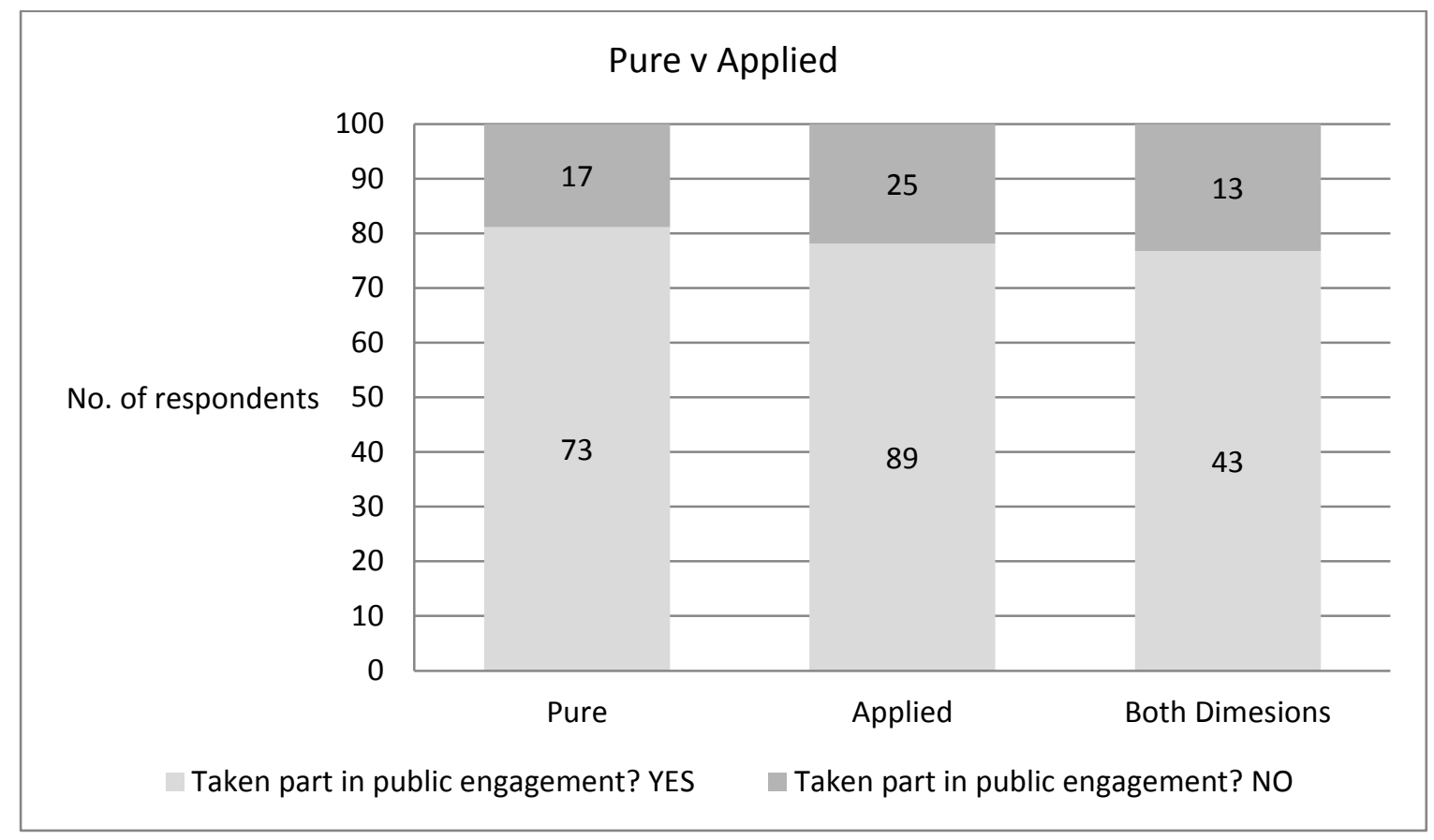

Figure 4: Pure v Applied disciplinary group distribution of respondents who took part in public engagement

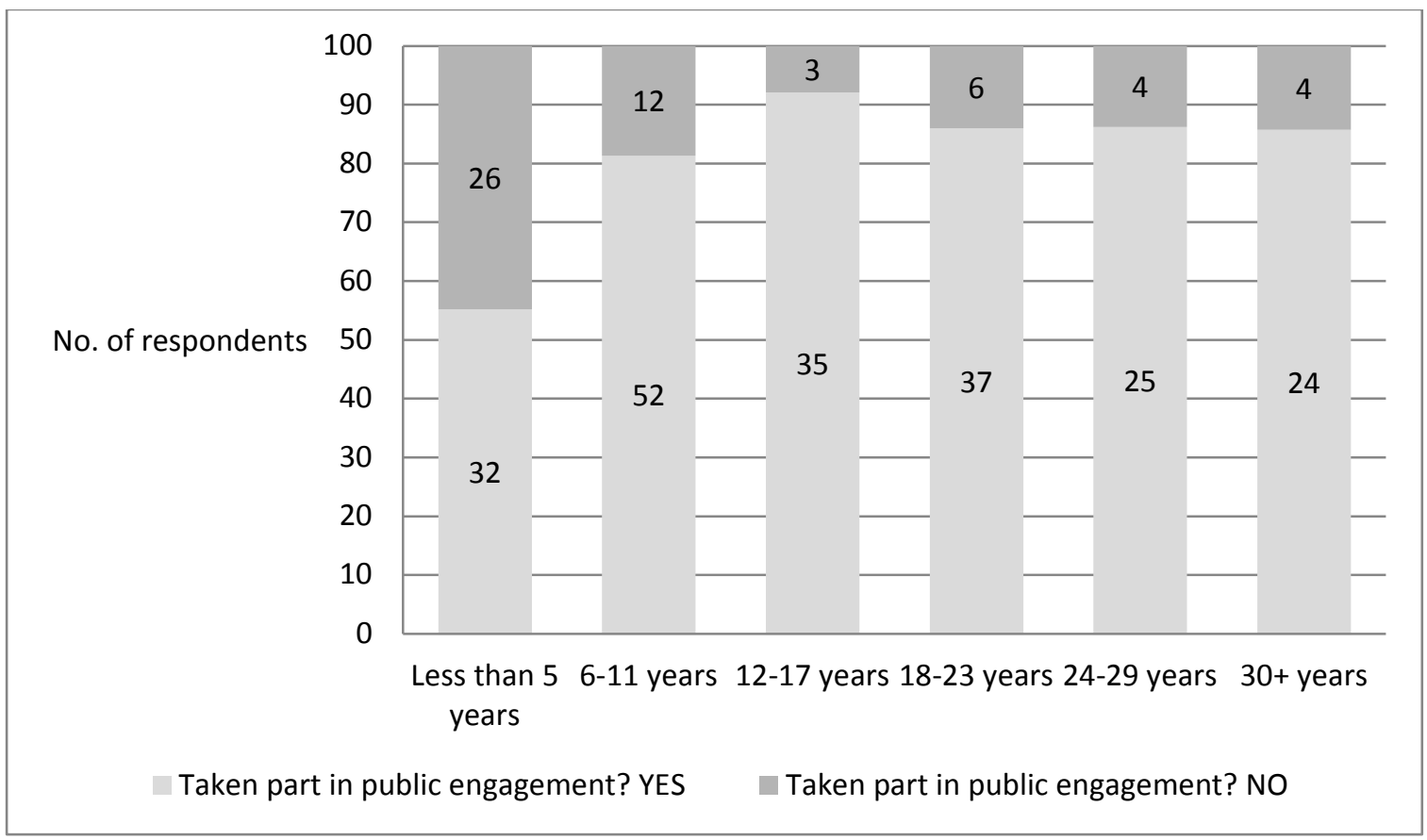

Figure 5: Research experience distribution of respondents who took part in public engagement 


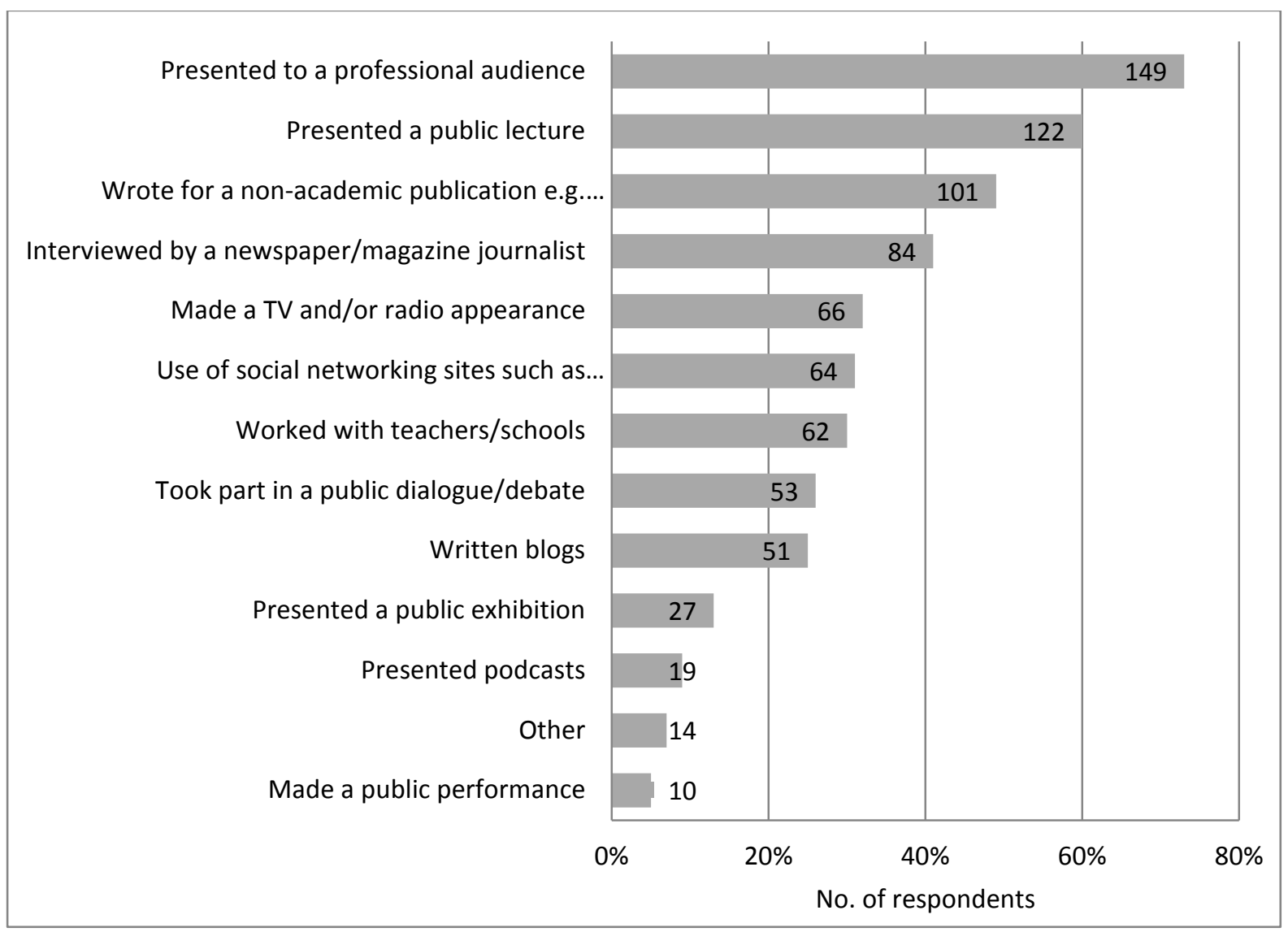

Figure 6: Types of public engagement activities $(n=205)$ 


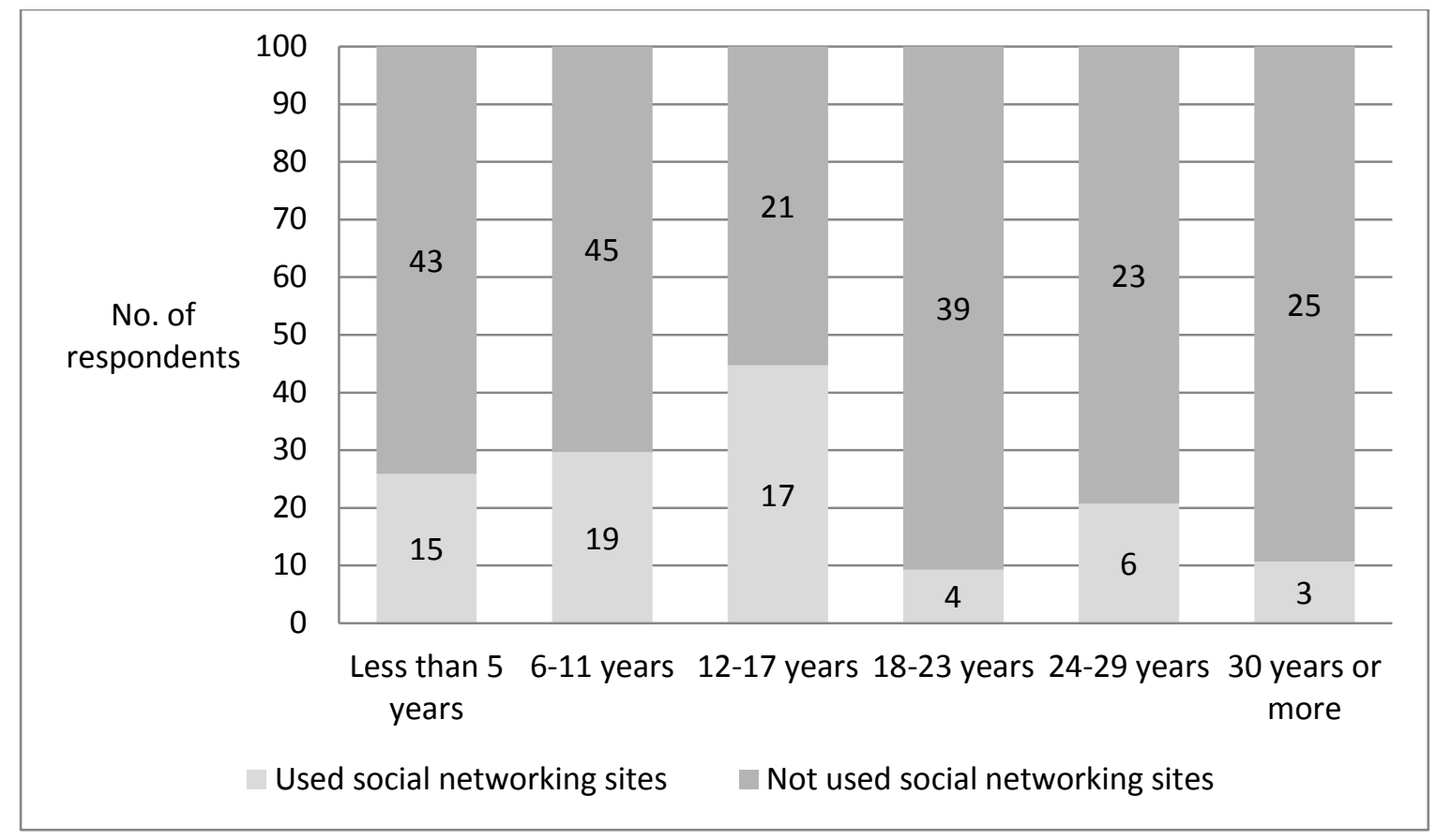

Figure 7: Research experience and use of social networking sites

Word Count - 6729 